Original article

\title{
MORPHOLOGICAL STUDY ON PERIADVENTITIAL ADIPOSE TISSUE OF THE AORTIC ARCH IN A RABBIT MODEL OF OBESITY: PRELIMINARY RESULTS
}

\author{
G. PENCHEV ${ }^{1}$, P. YONKOVA ${ }^{1}$, S. RIBARSKI ${ }^{2}$, D. KOSTOV ${ }^{1}$, E. VACHKOVA ${ }^{3}$, \\ N. GRIGOROVA ${ }^{3}$, T. M. GEORGIEVA ${ }^{3}$, ZH. IVANOVA $^{3} \&$ I. P. GEORGIEV ${ }^{3}$ \\ ${ }^{1}$ Department of Veterinary Anatomy, Histology and Embryology; \\ ${ }^{3}$ Department of Pharmacology, Animal Physiology and Physiological Chemis- \\ try, Faculty of Veterinary Medicine, Trakia University, Stara Zagora, Bul- \\ garia; ${ }^{2}$ Department of Morphology, Nutrition and Animal Physiology, Agri- \\ cultural Faculty, Trakia University, Stara Zagora, Bulgaria
}

\begin{abstract}
Summary
Penchev, G., P. Yonkova, S. Ribarski, D. Kostov, E. Vachkova, N. Grigorova, T. M. Georgieva, Zh. Ivanova \& I. P. Georgiev, 2018. Morphological study on periadventitial adipose tissue of the aortic arch in a rabbit model of obesity: Preliminary results. Bulg. J. Vet. Med., 21, No 2, 152-159.

This study was conducted to evaluate the effect of obesity on some morphological features of periadventitial adipose tissue in the aortic arch region. Twelve male white New Zealand rabbits were divided into two groups of 6 animals each: non-castrated non-obese and castrated-obese. Immediately after the rabbits were sacrificed samples from the aortic arch were collected, fixed in $10 \%$ neutral formalin for 24 hours, dehydrated and embedded in paraffin. Five $\mu \mathrm{m}$ sections were cut and stained with haematoxylin and eosin. Light microscopy of histological preparations from the aortic arch in the 2 groups showed that the periadventitial adipose tissue was represented of two fat depots. In the castrated and obese rabbits they were of bigger size compared with the lean animals. These greater fat depots were associated with hypertrophy of the adipocytes and increased number of blood vessels. The adipocytes of the fat depots from the two groups were unilocular and had the morphological characteristics of white adipose tissue. It may be concluded that obesity leads to increased mass of periadventitial adipose tissue, adipocytes hypertrophy and angiogenesis in the aortic arch.
\end{abstract}

Key words: angiogenesis, aortic arch, morphology, obesity, periadventitial adipose tissue, rabbits

\section{INTRODUCTION}

During the last decade the overweight and obesity have reached epidemic proportions worldwide, and are outlined as the major risk factors for a cluster of metabolic and vascular disorders (Bjørndal et al., 2011; Poledne et al., 2015). The 
atherosclerosis has been identified as one of the main risk factors for obesityassociated cardiovascular diseases, such as coronary artery disease, myocardial infraction and stroke (Kihara \& Matsuzawa, 2015; Poledne et al., 2015). Obesity is characterised by excessive accumulation of adipose tissue which is presently described not only as a major depot for storage of triglycerides, but functionally as a highly dynamic endocrine organ (Galic et al., 2010; Slavov \& Dzhelebov, 2010; Poledne et al., 2015). Adipose tissue secretes a large number of bioactive substances that are involved in the control of systemic insulin sensitivity, energy metabolism, immune response and cardiovascular homeostasis (Slavov \& Dzhelebov, 2010; Kihara et al., 2015). Moreover, the excessive fat accumulation is described as a low grade chronic inflammation which is involved in the pathogenesis of many of the obesity associated abnormalities, including atherosclerosis (Esser et al., 2014; Poledne et al., 2015).

The lipid profile and lipid metabolism in rabbits are similar to those of humans (the so-called LDL mammals) and differ from the most widely used experimental animals - mice and rats (the so-called HDL mammals) (Kawai et al., 2006; Georgiev et al., 2011; Niimi et al., 2016). Previously obtained results in our laboratory indicated that castrated rabbits developed obesity resembling to the central or visceral obesity in humans accompanied by increased intra-abdominal fat deposition (Georgiev et al., 2009; 2011). Moreover, the gradual decline in serum androgens with ageing in men is often associated with concomitant accumulation of central obesity, insulin resistance and cardio-vascular diseases (Isidori et al., 2005). That is why rabbits are increasingly used as an appropriate animal model to study various obesity-associated abnormalities in humans, such as metabolic syndrome, insulin resistance, type 2 diabetes and cardiovascular diseases (Zhao et al., 2007; Georgiev et al., 2009; 2011; Zheng et al., 2009; Waqar et al., 2010; Ivanova et al., 2015; Fan et al., 2015). Recently, a novel model for study of human hyperlipidaemia and atherosclerosis has been generated based in ApoE knockout rabbits (Ji et al., 2015; Niimi et al., 2016).

Most arteries are directly surrounded by adipose tissue, called perivascular adipose tissue. Both protective physiologic and pathologic properties for this tissue have been proposed (Gollasch \& Dubrovska, 2004; Fernandez-Alfonso et al., 2013). Growing evidence suggest regional differences in perivascular adipose tissue affecting vascular homeostasis, including inflammation and susceptibility (GilOrtega et al., 2015). For example the thoracic periaortic fat, surrounding the thoracic aorta in rodents is morphologically and functionally identical to brown adipose tissue, whereas white adipocytes surround abdominal aorta (Police et al., 2009; Gil-Ortega et al., 2015). It has been found that the expression of inflammatory genes and markers of immune cell infiltration was greater in abdominal than in thoracic perivascular adipose tissue (Padilla et al., 2013; Gil-Ortega et al., 2015). The majority of studies on perivascular adipose tissue have been performed in rodents. However, little is known about the morphological and functional features of periadventitial adipose tissue in rabbits.

Therefore, this study was conducted to investigate the effect of obesity on some morphological features of periadventitial adipose tissue of aortic arch in rabbits. 


\section{MATERIALS AND METHODS}

Animal experiments were conducted according to the Guide for the Care and Use of Laboratory Animals, and the Guidelines of the Animal Welfare Act, and approved by the Commission of Ethics at the Faculty of Veterinary Medicine of Trakia University, Stara Sagora.

The experiments were carried out with 12 male New Zealand White rabbits. At the beginning of the experiments they were between 3 and 3.5 months of age. The animals were housed in individual cages $(80 \times 60 \times 40 \mathrm{~cm})$ and the light/dark regime corresponded to the circadian cycle. They had free access to water and were fed a commercially available standard chow diet for adult rabbits. The health status of the animals was monitored by physical examination and observation of their behaviour, food and water intake and consistency of the faeces. In addition, rabbits were determined to be free of infection using routine microbiological testing.

The rabbits were randomly divided into 2 groups of 6 animals each that were matched according to initial body weights: $\mathrm{C}$ - castrated, obese (BW=3.210 $\pm 0.03 \mathrm{~kg}$ ) and $\mathrm{NC}$ - non-castrated, non-obese $(\mathrm{BW}=$ $3.085 \pm 0.04 \mathrm{~kg}$ ).

The obesity in rabbits was reproduced by castration, as previously described in details (Georgiev et al., 2009; 2011; Ivanova et al., 2015).

Two months after castration all rabbits were sacrificed and tissue samples from the aortic arch were immediately taken and fixed in $10 \%$ neutral formalin for 24 hours. Fixed tissue samples were dehydrated, embedded in paraffin, sectioned (5 $\mu \mathrm{m})$ at a rotary microtome (YD-335A, China) and stained with haematoxylin and eosin. Sections were examined by Primo Star photomicroscope (ZEISS, Germany).
Adipocytes diameter was measured on the cross section of the cells using software analysis (Soft Imaging System Gmbh, Germany).

The statistical analyses were performed using Statistica version 7.1 for Windows (StatSoft Inc., USA, 19842002). The mean and standard deviation (mean $\pm \mathrm{SD}$ ) were calculated according to the standard methods of the descriptive statistic. The ANOVA test was used to evaluate the effect of group (castration) on adipocytes diameter. When this effect was significant, the differences between groups were determined by means of the post hoc LSD test.

\section{RESULTS}

The results for the final body weight, body weight gain and body mass index are published elsewhere (Ivanova et al., 2015).

Routine light microscopy of aortic archs from the two groups of rabbits showed that the vascular wall consisted of three coats - tunica intima, tunica media and tunica adventitia, without any peculiarities. Around the third layer well differentiated depots of adipose tissue were observed. They were not situated on the entire circumference of the aorta, but at two almost symmetrical sites. In noncastrated (NC) rabbits these fat depots were comparatively well delineated and with a little area (Fig. 1A). In some sites infiltration of adipocytes into the aortic adventitia was found (Fig. 1B). In castrated and obese rabbits the size of the fat deposits was considerably larger (Fig. 2). Among the adipocytes a high density of blood vessels, predominantly capillaries, were observed (Fig. 3). In addition, the mean diameter of adipocytes in periadventitial adipose tissue of the aortic arch in obese rabbits $(56.05 \pm 11.27 \mu \mathrm{m})$ was sig- 

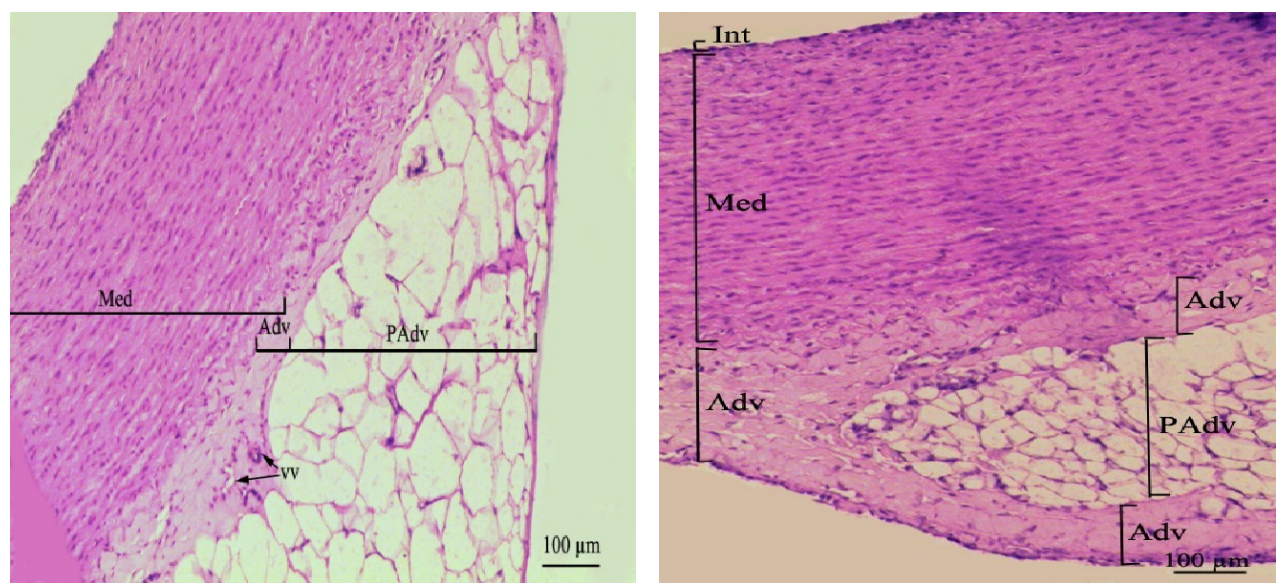

Fig. 1. Aortic arch, control group - non castrated, non-obese rabbits; Med - tunica media, Adv - tunica adventitia, Padv - periadventitial adipose tissue, Int - tunica intima, $\mathrm{vv}$ - vasa vasorum, $\mathrm{H} \& \mathrm{E}$, bar $=100 \mu \mathrm{m}$.

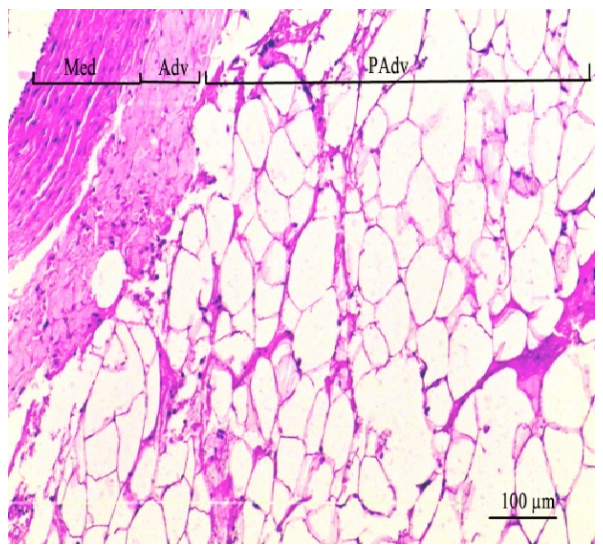

Fig. 2. Aortic arch, experimental group - castrated, obese rabbits; Med - tunica media, Adv - tunica adventitia, Padv - periadventitial adipose tissue, $\mathrm{H} \& \mathrm{E}$, bar $=100 \mu \mathrm{m}$.

nificantly $(\mathrm{P}<0.05)$ greater than in lean animals $(39.39 \pm 12.08 \mu \mathrm{m})$. In both groups of rabbits the adipocytes of periadventitial adipose tissue from the aortic arch were unilocular and had the morphological characteristics of white adipose tissue.

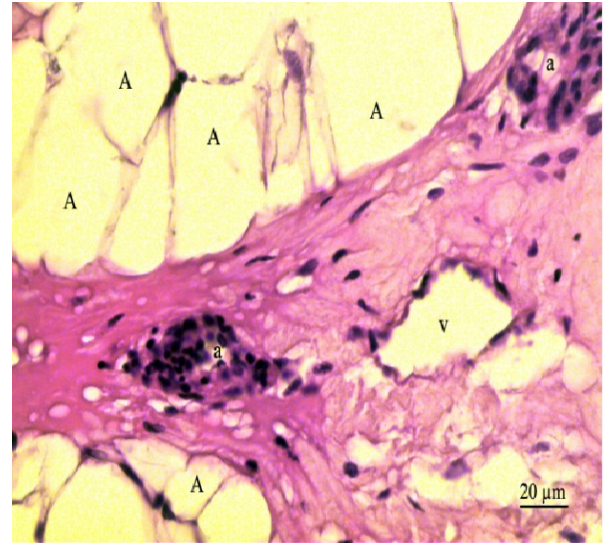

Fig. 3. Aortic arch, experimental group - castrated, obese rabbits; A - adipocytes of periadventitial adipose tissue, $\mathrm{a}-$ arteries, $\mathrm{v}-$ veins, $\mathrm{H} \& \mathrm{E}, \mathrm{bar}=20 \mu \mathrm{m}$.

\section{DISCUSSION}

In this study increased mass of periadventitial adipose tissue in aortic arch of obese rabbits was found. The greater adipocytes diameter in obese rabbits than in nonobese rabbits clearly indicated that the 
larger fat deposits in experimental group were associated with hypertrophy of the existing adipocytes. In addition, an increased density of capillaries in periadventitial adipose tissue of obese rabbits was established, demonstrating consolidated angiogenesis.

It should be emphasised that perivascular and epicardial fat are normally present in humans and other mammals. The obtained results in our study show that in the obese rabbits the size of the periadventitial fat depots and adipocytes from the aortic arch were much greater than in non-castrated non-obese rabbits and that these depots were composed of white adipose tissue. Therefore, this was not "ectopic fat" but rather hypertrophy of a normal anatomical structure.

However, it has been recently suggested that at least in rodents (rats and mice) perivascular adipose tissue was of different origin compared to white, brown and beige adipose tissue and thus may indeed be a fourth kind of adipose tissue (Brown et al., 2014). In addition, it has been found that perivascular adipose tissue differed from other adipose tissues by the presence of small number of brown adipocytes among their white variants (Szasz, 2012) and that it was more vascularised (Chatterjee et al., 2009).

In contrast to data in rodents (Henrichot et al., 2005), showing no changes in the size of the perivascular adipose tissue in the aortic arch, obese rabbits exhibited a marked increase in fat deposition. The observed differences among animal models imply that one has to be very careful when translating these results in humans where this tissue is not yet well characterised.

Chaldakov et al. (2012) defined the periadventitial adipose tissue in humans as a fourth layer in the wall of the blood ves- sels (tunica adiposa). However, our current results in rabbits clearly indicated that the periadventitial adipose tissue was confined to two separate depots, and was not presented as an entire layer around the tunica adventitia.

Previous studies in mice demonstrated that obesity was associated with an increase of macrophage infiltration and cytokine expression in periaortic adipose tissue surrounding the abdominal aorta (Eringa et al., 2007; Police et al., 2009; Cai et al., 2010). Dysfunction or an excess of perivascular adipose tissue is thought to directly induce inflammation, cell proliferation and endothelial disorders of the adjacent arteries (Ozen et al., 2015). Taking into account the fact that periadventitial adipose tissue of abdominal aorta is white adipose tissue, Padilla et al. (2013) point out that it is more susceptible to inflammation and more vulnerable to atherosclerosis than thoracic aorta where the perivascular adipose tissue is brown adipose tissue. Furthermore, it was found that there was no fascia between fat depots and arterial adventitia, thus allowing for easy access and paracrine effects of the secreted pro-inflammatory cytokines and adipokines to adjacent tissue (Britton \& Fox, 2011; Verhagen \& Visseren, 2011). This leads to influx of macrophages into the artery wall from "outside to inside", smooth muscle cells proliferation, endothelia dysfunction, hypercoagulability, increased chemotaxis and adhesion of monocytes to the endothelium (Verhagen \& Visseren, 2011; Brown et al., 2014). Therefore, the marked deposition of white adipose tissue in the aortic arch in obese rabbits could be considered as an early sign of the predisposition of vascular wall to atherosclerotic lesions. It can be hypothesised that perivascular adipose tissue may thus be involved in the pathogenesis 
of arteriosclerosis, plaque rupture, cardiovascular diseases (Sacks \& Fain, 2007; Takaoka et al., 2009; Verhagen \& Visseren, 2011; Virmani et al., 2005; De Marco et al., 2014; Fitzgibbons \& Czech, 2014).

The increased knowledge of perivascular adipose tissue function could bring up new therapeutic and preventive strategies for obesity-related cardiovascular diseases, and atherosclerosis in particular (Van de Voorde et al., 2014). The limitations of this study are the short experimental period and the lack of regional histological data of the aorta. Therefore, additional long-term studies are needed to better understand the role of the excessive periadventitial fat deposition in obesity and its possible involvement in pathogenetic mechanisms of atherosclerosis.

In conclusion, it might be assumed that castrated male New Zealand white rabbits could be used as an appropriate animal model to study some of the pathogenic mechanisms of obesity-associated cardiovascular abnormalities, especially those related to the role of perivascular adipose tissue for the initialisation of atherosclerosis.

\section{ACKNOWLEDGEMENTS}

The technical assistance of our students from Faculty of Veterinary Medicine in Stara Zagora - Venelin Hristov, Kristina Angelova and Simeon Tsonev is greatly appreciated.

\section{REFERENCES}

Bjørndal, B., L. Burri, V. Staalesen, J. Skorve \& R. K. Berge, 2011. Different adipose depots: Their role in the development of metabolic syndrome and mitochondrial response to hypolipidemic agents. Journal of Obesity, doi:10.1155/2011/490650.

Britton, K. A. \& C. S. Fox, 2011. Perivscular adipose tissue and vascular desease. Journal of Clinical Lipidology, 6, 79-91.
Brown, N. K., Z. Zhou, J. Zhang, R. Zeng, J. $\mathrm{Wu}$, D. T. Eitzman, Y. E. Chen \& L. Chang, 2014. Perivascular adipose tissue in vascular function and disease. A review of current research and animal models. Arteriosclerosis, Thrombosis, and Vascular Biology, 34, 1621-1630.

Cai, K., S. Caruthers, W. Huang, T. Williams, H. Zhang, S. Wickline, G. Lanza \& P. Winter, 2010. MR Molecular imaging of aortic angiogenesis. Journal of the American College of Cardiology, 3, 824-832.

Chaldakov, G., J. Beltowsky, P. Ghenev, M. Fiore, P. Panayotov, G. Rancic \& L. Aloe, 2012. Adipoparacrinology - vascular periadventitial adipose tissue (tunica adiposa) as an example. Cell Biology International, 36, 327-330.

Chatterjee, T. K., L. L. Stoll, G. M. Denning, A. Harrelson, A. L. Blomkalns, G. Idelman, F. G. Rothenberg, B. Neltner, S. A. Romig-Martin, E. W. Dickson, S. Rudich \& N. L. Weintraub, 2009. Proinflammatory phenotype of perivascular adipocytes influence of high-fat feeding. Circulation Research, 104, 541-549.

De Marco, V., A. Aroor \& J. Sowers, 2014. The pathophysiology of hypertension in patients with obesity. Nature Reviews Endocrinology, 10, 346-376.

Eringa, E., W. Bakker, Y. Smulders, E. Serme, J. Yudkin \& C. Stehouwer, 2007. Regulation of vascular function and insulin sensitivity by adipose tissue: Focus on perivascular adipose tissue. Microcirculation, 14, 389-402.

Esser, N., S. Legrand-Poels, J. Piette, A. J. Scheen \& N. Paquot, 2014. Inflammation as a link between obesity, metabolic syndrome and type 2 diabetes. Diabetes Research and Clinical Practice, 105, 141150.

Fan, S. Kitajima, T. Watanabe, J. Xu, J. Zhang, E. Liu \& Y. E. Chen, 2015. Rabbit models for the study of human atherosclerosis: From pathophysiological mechanisms to translational medicine. Pharmacology \& Therapeutics, 146, 104-119. 
Fernandez-Alfonso, M., M. Gil-Ortega, C. Garcia-Prieto, I. Aranguez, M. Ruiz-Gayo \& B. Somoza, 2013. Mechanisms of perivascular adipose tissue dysfunction in obesity. International Journal of Endocrinology, doi: 10.1155/2013/402053.

Fitzgibbons, T. \& M. Czech, 2014. Epicardial and perivascular adipose tissue and their influence on cardiovascular desease: Basic mechanisms and clinical associations. Journal of the American Heart Association, 3, doi: 10.1161/JAHA.113.000582.

Galic, S., J. S. Oakhill \& G. R. Steinberg, 2010. Adipose tissue as an endocrine organ. Molecular and Cellular Endocrinology, 316, 129-139.

Georgiev, I. P., I. N. Kanelov, T. M. Georgieva, V. Ivanov, S. Dimitrova, Y. Iliev, J. Nikolov, L. Lazarov \& A. Roussenov, 2009. Evaluation of insulin resistance in obese castrated New Zealand white rabbits. Revue de Médecine Vétérinaire, 160 , 335-340.

Georgiev, I. P., T. M. Georgeva, V. Ivanov, S. Dimitrova, I. Kanelov, T. Vlaykova, S. Tanev, D. Zaprainova, E. Dichlianova, G. Penchev, L. Lazarov, E. Vachkova \& A. Roussenov, 2011. Effects of castration-induced visceral obesity and antioxidant treatment on lipid profile and insulin sensitivity in New Zealand white rabbits. Research in Veterinary Science, 90, 196-204.

Gil-Ortega, M., B. Somoza, Y. Huang, M. Gollasch \& M. S. Fernandez-Alfonso, 2015. Regional differences in perivascular adipose tissue impacting vascular homeostasis. Trends in Endocrinology \& $\mathrm{Me}$ tabolism, 26, 367-375.

Gollasch, M. \& G. Dubrovska, 2004. Paracrine role for periadventitial adipose tissue in the regulation of arterial tone. Trends in Pharmacological Sciences, 25, 647-653.

Henrichot, E., C. Juge-Aubry, A. Pernin, J. Pache, V. Velebit, J. Dayer, P. Meda, C .Chizzolini \& C. Meier, 2005. Production of chemokines by perivascular adipose tissue: a role in the pathogenesis of athero- sclerosis? Arteriosclerosis, Thrombosis, and Vascular Biology, 25, 2594-2599.

Isidori, A., E. Giannetta, E. Greco, D. Gianfrilli, V. Bonifacio, A. Isidori, A. Lenzi \& A. Fabbri, 2005. Effects of testosterone on body composition, bone metabolism and serum lipid profile in middle-aged men: A meta-analysis. Clinical Endocrinology, 63, 280-293.

Ivanova, Z., B. Bjørndal, N. Grigorova, A. Roussenov, E. Vachkova, K. Berge, L. Burri, R. Berge, S. Stanilova, A. Milanova, G. Penchev, R. Vik, V. Petrov, T. M. Georgieva, B. Bivolarski \& I. P. Georgiev, 2015. Effect of fish and krill oil supplementation on glucose tolerance in rabbits with experimentally induced obesity. European Journal of Nutrition, 54, 1055-1067.

Ji, D., G. Zhao, A. Songstad, X. Cui \& E. J. Weinstein, 2015. Efficient creation of an APOE knockout rabbit. Transgenic Research, 24, 227-235.

Kawai, T., T. Ito, K. Ohwada, Y. Matsushita \& H. Tomoike, 2006. Hereditary postprandial hypertriglyceridemic rabbit exhibits insulin resistance and central obesity. A novel model of metabolic syndrome. Arteriosclerosis, Thrombosis, and Vascular Biology, 26, 2752-2757.

Kihara, S. \& Y. Matsuzawa, 2015. Fat distribution and cardiovascular disease risk. Current Cardiovascular Risk Reports, 9, 1-6.

Niimi, M., D. Yang, S. Kitajima, B. Ning, C. Wang, S. Li, E. Liu, J. Zhang, Y. E. Chen \& J. Fan, 2016. ApoE knockout rabbits: A novel model for the study of human hyperlipidemia. Atherosclerosis, 245, 187-193.

Ozen, G., A. Daci, X. Norel \& G. Topal, 2015. Human perivascular adipose tissue dysfunction as a cause of vascular disease: Focus on vascular tone and wall remodelling. European Journal of Pharmacology, 766, 16-24.

Padilla, J., N. Jenkins, V. Vieira-Potter \& M. Laughlin, 2013. Divergent phenotype of rat thoracic and abdominal perivascular 
G. Penchev, P. Yonkova, S. Ribarski, D. Kostov, E. Vachkova, N. Grigorova, T. M. Georgieva...

adipose tissue. American Journal of Physiology, 304, 543-552.

Poledne, R., I. K. Lesná \& S. Cejková, 2015. Adipose tissue and atherosclerosis. Physiological Research, 64, 395-402.

Police, S., S. Thatcher, R. Charmigo, A. Daugherty \& L. Cassis, 2009. Obesity promotes inflammation in periaortic adipose tissue and angiotensin II-induced abdominal aortic aneurysm formation. Arteriosclerosis, Thrombosis, and Vascular Biology, 29, 1458-1464.

Sacks, H. \& J. Fain, 2007. Human epicardial adipose tissue: A review. American Heart Journal 153, 907-917.

Slavov, E. P. \& P. V. Dzhelebov, 2010. Basic endocrine products of adipose tissue - a review. Bulgarian Journal of Veterinary Medicine, 13, 199-210.

Szasz, T. \& R. C. Webb, 2012. Perivascular adipose tissue: More than just structural support. Clinical Science, 122, 1-12.

Takaoka, M., D. Nakata, S. Kihara, I. Shimomura, Y. Kimura, Y. Tabata, Y. Saito, R. Nagai \& M. Sata, 2009. Periadventitial adipose tissue plays a critical role in vascular remodelling. Circulation Research, 105, 906-911.

Van de Voorde, J., C. Boydens, B. Pauwels \& K. Decaluwe, 2014. Perivascular adipose tissue, inflammation and vascular dysfunction in obesity. Current Vascular Pharmacology, 12, 403-411.

Verhagen, S. \& F. Visseren, 2011. Perivascular adipose tissue as a cause of atherosclerosis. Atherosclerosis, 214, 3-10.

Virmani, R., F. Kolodge, A. Burke, A. Finn, H. Gold, T. Tulenko, S. Wrenn \& J. Narula, 2005. Atherosclerotic plaque progression and vulnerability to rupture: angiogenesis as a source of intraplaque hemor- rhage. Arteriosclerosis, Thrombosis, and Vascular Biology, 10, 2054-2061.

Waqar, A. B., T. Koike, Y. Yu, T. Inoue, T. Aoki, E. Liu \& J. Fan, 2010. High-fat diet without excess calories can induce metabolic disorders and enhances atherosclerosis in rabbits. Atherosclerosis, 213, 148 155.

Zhao, S., Y. Chu, C. Zhang, Y. Lin, K. Xu, P. Yang, Q. Yu, J. Fan \& E. Liu, 2007. Dietinduced central obesity and insulin resistance in rabbits. Journal of Animal Physiology and Animal Nutrition, 92, 105-111.

Zheng, H., C. Zhang, Y. Wang, Y. Lin, P. Yang, Q. Yu, J. Fan \& E. Liu, 2009. Fat and cholesterol diet induced lipid metabolic disorders and insulin resistance in rabbit. Experimental and Clinical Endocrinology \& Diabetes, 117, 400-405.

Paper received 07.11.2016; accepted for publication 06.02.2017

\section{Correspondence:}

Ivan Penchev Georgiev

Department of Pharmacology, Animal Physiology and Physiological Chemistry,

Faculty of Veterinary Medicine, Trakia University, 6000 Stara Zagora, Bulgaria tel. +359042699629 e-mail: ivanpenchev@uni-sz.bg 